\title{
Formulation and Investigation Antioxidant of O/W Cream Containing Euphorbia hirta L. Herb Extract
}

\author{
Fadli A. Gani ${ }^{1}$, Nadia Isnaini ${ }^{2, *}$, and Siti Maryam ${ }^{3}$ \\ ${ }^{1}$ Faculty of Veterinary Medicine, Syiah Kuala University, Aceh, Indonesia \\ ${ }^{2}$ Faculty of Pharmaceutical Sciences, Prince of Songkla University, Hat Yai, Thailand \\ ${ }^{3}$ Faculty of Teacher Training and Education, Syiah Kuala University, Aceh, Indonesia
}

\begin{abstract}
The herb extract of Euphorbia hirta L. have been reported as sources of inexpensive antioxidant that can be used as potential cosmetic product. Therefore, the aims of this study were to formulate E. hirta L. extract loaded cream and to assess the antioxidant activity of loaded cream. First, E. hirta L. was prepared with maceration process using water as solvent (1:5). Afterwards, the obtained extract was subjected to a lyophilisation process. The extract was tasted for antioxidant activity using 2,2-diphenyl-1-picrylhydrazyl (DPPH) for suitable concentration of the extract incorporated into the cream, which was $10 \% \mathrm{w} / \mathrm{w}$. The cream was formulated as $\mathrm{o} / \mathrm{w}$ emulsion and stearic acid was selected as an emulsifier. The extract loaded cream was tested $\mathrm{pH}$, viscosity, and antioxidant. The freshly prepared extract loaded cream was dark green and no phase separation was observed after centrifugation at 3,000 rpm for $30 \mathrm{~min}$. They had acidic $\mathrm{pH}$ (4.4-5.1), considered acceptable for skin application, especially in skin face. The DPPH measurement revealed that the formulation had potential antioxidant activity with $\% \mathrm{SCV}$ more than $80 \%$ at $100 \mu \mathrm{g} / \mathrm{mL}$. In conclusion, topical o/w cream containing extract was successfully prepared with substantial antioxidant activity and was displayed a potential use in cosmetic formulations, especially antiaging products.
\end{abstract}

Keywords: Euphorbia hirta extract, cream, antioxidant, topical delivery.

\section{Introduction}

Nowadays, the cosmetic product has been conducted using plant extract as the active compounds. The one of plant extract that commonly used in the cosmetic product is Euphorbia hirta Linn. The herb of E. hirta L. extract possesses antioxidant activity that can be very promising for antiaging products. According to Asha, Thirunavukkarasu [1], shown a high amount of phenol and flavonoid content. Phenol and flavonoid have been known as an antioxidant agent in plants [2]. Therefore, would have a potential sign in reducing or preventing oxidation. In the current study, the leave extract was prepared using water as a solvent. followed by the lyphophilization process.

The cream base was oil in water type as a vehicle for obtaining good skin feeling, ease of application and aesthetic appearance. The oil and water phases were emulsified by using stearic acid. The beaker method was employed to prepare the cream. After mixing oil phase and water phase, a suitable amount of herb extract based on the antioxidant activity $\left(\mathrm{EC}_{50}\right.$, the effective concentration of sample required to scavenging DPPH radical by $50 \%$ ) was incorporated into the cool cream and evaluated for their physicochemical properties and antioxidant activity. The aims of the current work were to prepare herb extract using the solvent extraction method, to formulate $\mathrm{o} / \mathrm{w}$ cream containing herb extract and to investigate the antioxidant potential of the cream containing herb extract.

\section{Materials and Methods}

\subsection{Materials}

The fresh herb was collected from Darussalam, Banda Aceh, Aceh, Indonesia and identified by the Indonesian Institute of Sciences (LIPI). Stearic acid, Lanolin anhydrous, Triethanolamine, and Propylene glycol were supplied by Chemipan Corporation Co., Ltd (Bangkok, Thailand). L-ascorbic acid (analytical grade) was purchased from S.M. Chemical Supplied Co., Ltd (Bangkok, Thailand). Distilled water was used in a whole experiment. All the chemicals, except L-ascorbic acid, was pharmaceutical grade.

\subsection{Preparation of Euphorbia hirta L. Herb Extract}

E. hirta L. herbs were mixed with water as solvent (tamarind: solvent $=1: 5$ ) and homogenized by Panasonic MX-GX1462 blender. Then the preparation process was based on the published papers [3, 4]. 


\subsection{Preparation of Formulation}

The concentration of herb extract used was 10\%w/w (25times of $\mathrm{EC}_{50}$ ) according to antioxidant activity of herb extract $\left(\mathrm{EC}_{50}=3.805 \mathrm{mg} / \mathrm{mL}\right)$. The excipients of cream consisted of stearic acid (emulsifier), lanolin anhydrous (emollient), triethanolamine (neutralizer), propylene glycol (humectant), and water as the vehicle (Table 1). $1 \% \mathrm{w} / \mathrm{v}$ Ethylhexyl glycerine and $0.2 \% \mathrm{w} / \mathrm{v}$ phenoxyethanol were used as preservatives.

Table 1. The composition of herb extract loaded cream.

\begin{tabular}{ccc}
\hline & \multicolumn{2}{c}{$\% \mathrm{w} / \mathrm{w}$} \\
\cline { 2 - 3 } Ingredient & $\mathrm{F} 0$ & $\mathrm{~F} 1$ \\
\cline { 2 - 3 } herb extract & - & 10 \\
Stearic acid & 25.0 & 25.0 \\
Lanolin anhydrous & 4.0 & 4.0 \\
Triethanolamine & 1.5 & 1.5 \\
Propylene glycol & 9.0 & 9.0 \\
Ethylhexyl \\
glycerine
\end{tabular}

Briefly, the creams (emulsion type) were prepared with a beaker method. The oil phase and water phase were heated until $700^{\circ} \mathrm{C}$ on a water bath. Then, the oil phase was added into the water phase and stirred continuously until homogeneous. The emulsions were obtained after cooling down in room temperature and E. hirta L. herb extract was added into the emulsion bases. The formulation without $E$. hirta $\mathrm{L}$. herb extract was named as F0, whereas the formulation which contained E. hirta L. herb extract was named F1

\subsection{Physicochemical properties of formulations}

\subsubsection{Centrifugation test}

The stability of freshly prepared formulations was determined with centrifugation test at $3000 \mathrm{rpm}$ for 30 min. Then, the appearance and phase separation were observed by macroscopic observation.

\subsection{2 $\mathrm{pH}$ measurement}

The $\mathrm{pH}$ of the formulations was measured by a digital $\mathrm{pH}$ meter at room temperature $\left(30 \pm 2^{\circ} \mathrm{C}\right),(n=3)$.

\subsubsection{Viscosity and flow measurement}

The viscosity and rheological properties of the formulations were assessed using a bob cup Brookfield rheometer (model LVDV-III Ultra, Brookfield Engineering Laboratories Inc., MA, USA) and small adapter. The spindle SC4-31 was used. The measurements were performed at room temperature $\left(30 \pm 2^{\circ} \mathrm{C}\right),(n=3)$.

\subsection{Antioxidant test}

In this study, 2, 2-diphenyl-1-picrylhydrazyl (DPPH) assay was used to measure the scavenging ability of both herb extract and the cream formulations. The DPPH test was performed using a 96-well plate and a microplate reader (NS-100 Nano scan, Hercuvan Lab Systems, UK). Firstly, the $\mathrm{EC}_{50}$ of herb extract was determined to find the suitable concentration used in the cream. The test concentrations of herb extract were 0.78 to $40 \mathrm{mg} / \mathrm{mL}$.

The concentrations of formulation were fixed as 25 , 50 , and $100 \mu \mathrm{L} / \mathrm{mL}$. The positive control was L-ascorbic acid $(0.1-50 \mu \mathrm{g} / \mathrm{mL}$ diluted in water), while the samples (weight $2 \mathrm{~g}$ ) were mixed with $2 \mathrm{~mL}$ of distilled, vortexed, and sonicated for $30 \mathrm{~min}$ to obtain the clear solution. Then, the samples were mixed with the DPPH solution. The DPPH solution at the concentration of $6 \times 10^{-5} \mathrm{M}$ was prepared in absolute ethanol. The mixtures were incubated in the dark at room temperature for 25 minutes and measured spectrophotometrically at $517 \mathrm{~nm}$. The scavenging activity of formulations was calculated using the following equation:

Scavenging activity $(\%)=\frac{1 \text {-absorbance of sample }}{\text { absorbance of control }} \times 100$ (1)

\subsection{Statistical analysis}

Data were expressed as mean \pm standard deviation (SD). Statistical comparisons were made using Student's t-test performed by SPSS statistics 20 (SPSS, Cary, NC, USA). Differences at $\mathrm{p}<0.05$ were considered to be significant.

\section{Results and Discussion}

\subsection{Preparation of Euphorbia hirta L. herb extract}

The percent yield of E. hirta L. extract was $40.36 \%$. The crude extract had dark green colored and chlorophyll smell.

\subsection{Antioxidant activity of Euphorbia hirta L. herb extract}

Before being loaded into the formulation, screening of antioxidant activity of $E$. hirta L. herb extract was carried out using the DPPH technique. The $\mathrm{EC}_{50}$ values were values of $E$. hirta L. herb extract was $3.805 \mathrm{mg} / \mathrm{mL}$. However, its $\mathrm{EC}_{50}$ was markedly higher than that of the positive control, ascorbic acid $\left(\mathrm{EC}_{50}=2.9045 \mu \mathrm{g} / \mathrm{mL}\right)$. 
This phenomenon may be related to a lot of substances contained in the extract.

\subsection{Preparation of formulations}

Both cream base and E. hirta L. herb extract loaded cream were successfully prepared without any phase separation. This was due to the appropriate of stearic acid used in the formulation $(25 \% \mathrm{w} / \mathrm{w})$. The macroscopic observation revealed that the formulation F1 was homogeneous with the dark green color. The prepared cream had the high aqueous proportion (water and propylene glycol) at about $50-60 \% \mathrm{w} / \mathrm{w}$ and contained the plant extract. Thus, suitable preservatives were added to inhibit bacterial growth.

\subsection{Physicochemical properties of formulations}

\subsubsection{Centrifugation test}

All formulations remained homogeneous after 3,000 rpm centrifugation (30 min). Thus, the prepared creams were considered stable under this experimental condition. It has been reported that the separation of two phases in the emulsion system can affect several characteristics, especially solubility of active ingredients(s) [5], which is not the case for the current work.

It is generally recognized the cream are a formulation with high water content [6]. In prepared creams, percentages of water content started from 49.30 to $59.30 \% \mathrm{w} / \mathrm{w}$. Electrical conductivity is associated with the ability of water to pass an electrical current [7]. According to conductivity values summarized in Table 2., the high values indicated the o/w type-emulsions. The negative charge of ions in the formulations can affect the conductivity values [8].

\subsection{2 $\mathrm{pH}$ measurement}

The $\mathrm{pH}$ of the formulations were decreased significantly after addition of E. hirta L. herb extract ( $<<0.05)$. This phenomenon may be related to the content of organic acids in the extract. However, the $\mathrm{pH}$ values of the E. hirta L. herb extract loaded formulations were considered in the range of skin $\mathrm{pH}$ values

Table 2. $\mathrm{pH}$ values and electrical conductivity values of formulations (mean $\pm \mathrm{SD}, \mathrm{n}=3$, where $\mathrm{n}$ is the number of samples).

\begin{tabular}{ccc}
\hline Parameters & F0 & F1 \\
\hline $\mathrm{pH}$ value & $6.20 \pm 0.00$ & $5.90 \pm 0.00$ \\
$\begin{array}{c}\text { Electrical conductivity } \\
(\mu \mathrm{s} / \mathrm{cm})\end{array}$ & $58.19 \pm 1.11$ & $75.99 \pm 1.21$ \\
\hline
\end{tabular}

\subsubsection{Viscosity and rheological measurement}

The flow characteristic comparison of three formulations are displayed in Figure 1. According to Figure 1, in general, the viscosity of the creams tended to decrease when the shear rates increased. The prepared lotions appeared to exhibit a shear-thinning system (NonNewtonian flow). The viscosity of the formulations decreased when the shear rates increased. At speeds of 45, 60 and $90 \mathrm{rpm}$, there was no statistical difference in the viscosity between $F 0$ and $F 1$ ( $p>0.05$ ). The viscosity values of the tamarind fruit pulp extract loaded formulations were rather low $<1,000 \mathrm{cps}$. Therefore, they are expected to be easily applied to the skin surface.

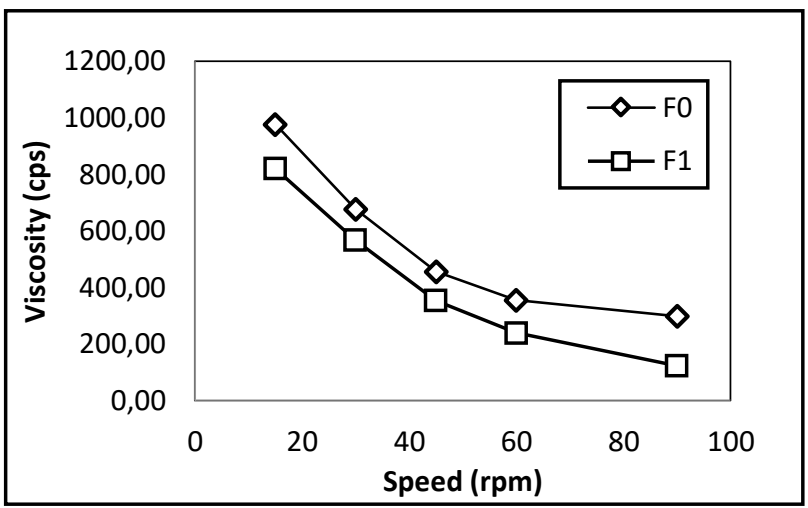

Figure 1. The rheograms of $\mathrm{F} 0$ and $\mathrm{F} 1$ determined at room temperature $\left(30 \pm 2^{\circ} \mathrm{C}\right)$, (mean $\pm \mathrm{SD}, \mathrm{n}=3$, where $\mathrm{n}$ is the number of samples).

\subsection{Antioxidant activity of Euphorbia hirta L. herb extract loaded cream}

For the cream formulations, the radical scavenging activity was expressed as the percentage of reduction of initial radical absorbance by formulations at different concentrations (Table 3). Ascorbic acid was used as a positive control with the $\mathrm{EC}_{50}$ of $2.795 \mu \mathrm{g} / \mathrm{mL}$. The unloaded formulation (F0) did not have any antioxidant activity (negative values) based on \%SCV activity values at all concentrations tested. In contrast, E. hirta L. herb extract displayed the existence of antioxidant activity as shown in Table 3. According to these results, it can be speculated that the antioxidant properties were solely caused by $E$. hirta L. herb extract which was incorporated in the cream base.

Table 3. \% Scavenging activity of F1 (10\%w/w E. hirta L. extract), (mean $\pm \mathrm{SD}, \mathrm{n}=5$ where $\mathrm{n}$ is a number of replications).

\begin{tabular}{ccc}
\multirow{2}{*}{$\begin{array}{c}\text { Concentrations } \\
(\mu \mathrm{g} / \mathrm{mL})\end{array}$} & \multicolumn{2}{c}{$\%$ Scavenging activity } \\
\cline { 2 - 3 } & $\mathrm{F} 0$ & $\mathrm{~F} 1$ \\
\hline 25 & $-51.87 \pm 2.34$ & $21.65 \pm 0.88$ \\
50 & $-58.19 \pm 3.11$ & $48.28 \pm 0.13$ \\
100 & $-67.09 \pm 3.21$ & $87.89 \pm 0.53$
\end{tabular}




\section{Conclusion}

The current results demonstrated that E. hirta L. extract was successfully incorporated into $\mathrm{o} / \mathrm{w}$ cream which contained the suitable amount of stearic acid. The E. hirta L. extract loaded cream had acceptable physicochemical properties based on macroscopic observation, $\mathrm{pH}$, and viscosity measurements. These loaded cream also had satisfactory antioxidant activity, which can be regarded as an effective and economical skincare product for topical uses.

\section{Acknowledgments}

We are thankful to The Faculty of Pharmaceutical Sciences, Prince of Songkla University, Thailand for the facility and equipment.

\section{References}

1. Asha S, Thirunavukkarasu P, Mani VM, et al. : Antioxidant Activity of Euphorbia hirta Linn Leaves Extracts. European Journal of Medicinal Plants. 2016;14(1):1-14.

2. Tawaha K, Alali FQ, Gharaibeh M, et al. : Antioxidant Activity and Total Phenolic Content of Selected Jordanian Plant Species. Food chemistry. 2007;104(4):1372-8.
3. Gupta C, Prakash D, Gupta S: Studies on the Antimicrobial Activity of Tamarind (Tamarindus indica) and Its Potential as Food Bio-Preservative. International Food Research Journal. 2014;21(6):243741.

4. Viyoch J, Patcharaworakulchai P, Songmek R, et al. : Formulation and Development of a Patch Containing Tamarind Fruit Extract by Using The Blended Chitosan-starch as a Rate-controlling Matrix. International Journal of Cosmetic Science. 2003;25(3):113-25.

5. Mhatre S, Vivacqua V, Ghadiri M, et al. : Electrostatic Phase Separation: A review. Chemical Engineering Research and Design. 2015;96:177-95.

6. Anton N, Akram S, Vandamme TF : Transitional Nanoemulsification Methods Nanoemulsions New York, USA: Elsevier. https://doi. org/10.1016/B978-0-12811838-2.00004-7; 2018.

7. Shoghl SN, Jamali J, Moraveji MK: Electrical Conductivity, Viscosity, and Density of Different Nanofluids: An Experimental Study. Experimental Thermal and Fluid Science. 2016;74:339-46.

8. Amani M, Amani P, Kasaeian A, et al.: Thermal Conductivity Measurement of Spinel-Type Ferrite $\mathrm{MnFe}_{2} \mathrm{O}_{4}$ Nanofluids in The Presence of A Uniform Magnetic Field. Journal of Molecular Liquids. 2017; 230:121-8. 